This is a postprint version of the following published document:

Shabestari, M. E., Kalali, E. N., González, V. J., Wang, D. Y., Fernández-Blázquez, J. P., Baselga,

J. \& Martín, O. (2017). Effect of nitrogen and oxygen doped carbon nanotubes on flammability of epoxy nanocomposites. Carbon, 121, pp. 193-200.

DOI: 10.1016/j.carbon.2017.05.087

(C) Elsevier, 2017

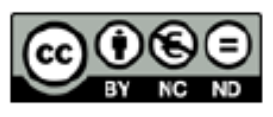

This work is licensed under a Creative Commons Attribution-NonCommercialNoDerivatives 4.0 International License. 


\title{
Effect of nitrogen and oxygen doped carbon nanotubes on flammability of epoxy nanocomposites
}

\author{
Marjan E. Shabestari ${ }^{a}$, Ehsan N. Kalali ${ }^{\text {b }}$, Viviana Jehová González ${ }^{c}$, De-Yi Wang ${ }^{d}$, \\ Juan P. Fernández-Blázquez ${ }^{d}$, Juan Baselga ${ }^{a}{ }^{*}$, Olga Martin ${ }^{a}$

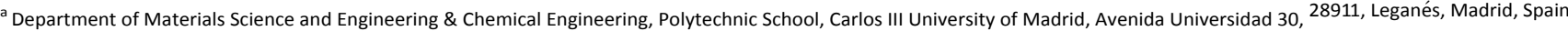 \\ b Jinzhai Road 96, State Key Laboratory of Fire Science, University of Science and Technology of China, Hefei, 230026, Anhui, PR China \\ ' Departamento de Química Orgánica, Inorgánica y Bioquímica, Facultad de Ciencias y Tecnologías Químicas, IRICA, Universidad de Castilla La Mancha, 13071 , Ciudad Real, Spain \\ ${ }^{d}$ IMDEA Materials Institute, c/Eric Kandel 2, Getafe Madrid, 28906, Spain
}

\begin{abstract}
To overcome the flammability of epoxy resins, novel nitrogen $\left(\mathrm{CN}_{\mathrm{X}}\right)$ and oxygen $\left(\mathrm{CO}_{\mathrm{X}}\right)$ doped CNT were synthesized via CVD method and epoxy nanocomposites at 2 wt.\%. constant loading were prepared by three roll milling and cured. The structures of the nanotubes were confirmed by XRD, XPS, SEM and Raman and it was found a very high aspect ratio especially for $\mathrm{CO}_{\mathrm{X}}$.

Thermal degradation as well as glass transition temperatures and elastic moduli were measured by TGA, DSC and DMTA. The flammability of epoxy nanocomposites was studied by microscale combustion calorimetry (MCC) and limiting oxygen index (LOI) determination. Results showed that the fire retardant properties of nanocomposites improved significantly specially for $\mathrm{CO}_{\mathrm{X}}$, which presented a very high LOI (35\%) and a homogeneous and uniform surface after burning. This effect was tentatively attributed to the very high aspect ratio of $\mathrm{CO}_{\mathrm{x}}$ tubes.
\end{abstract}

\section{Introduction}

Since the accidental discovery by Sumio lijima in the soot of the arcdischarge method [1] in 1991, carbon nanotubes (CNTs) have generated a great deal of research in most areas of science and engineering due to their extraordinary properties: stronger than steel, harder than diamond and electrical conductivity higher than copper [2].

It is well understood that CNTs could not be utilized alone without any supporting medium. In the other words, many of these noticeable properties can be best obtained by incorporating the CNTs into some form of matrix to make different composites. In many cases, these composites have employed polymer matrices and nowadays CNT nanocomposites are being used in many research areas and commercial products due to their mechanical, thermal, optical, electrical [3], photocatalytic properties [4], with applications ranging from coatings [5], batteries [6], filters [7], bio sensors [8] to flame retardant additives [9].

Epoxy resins (EP) are low-molecular-weight pre-polymers containing more than one epoxide group, which are cured using a wide variety of curing agents (amines, anhydrides, etc.). The EPs are widely used as advanced matrix resins in the electrical, electronic, aerospace industries and anticorrosion coatings due to their outstanding characteristics such as high tensile and impact strength, good fatigue resistance, micro cracking resistance, chemical and corrosion resistance, excellent electric insulation and low manufacturing cost [10].

However, the development and application of epoxy based composites has been greatly limited by their high flammability [11]; improving the flame retardancy properties of epoxy resins has become therefore very attractive and has absorbed the attention of many researchers for advanced application. Tradi-tionally, halogenated compounds have been widely used to enhance the flame retardant properties of epoxy resins [12]. Currently, various compounds containing metal hydroxides [13,14], nitrogen, phosphorus [15e17], boron and silicon [18,19], have gained much attention as flame retardants for polymer 
materials to replace traditional toxic halogen-containing flame retardants. The major problem encountered with these com-pounds is the high loadings needed to achieve high level of fire resistance which generally cause deterioration of the mechanical behavior [20]. The arising of nanocomposite technology has pro-vided a revolutionary new solution to flame retardant polymer materials, improving the fire resistance just at a very low loading of nano-fillers ( $<10 \mathrm{wt. \%}$ ) [21], compared to conventional fillers such as $\mathrm{Mg}(\mathrm{OH})_{2}$ or $\mathrm{Al}(\mathrm{OH})_{3}$ (40 wt.\% to 60 wt.\% loading) [22]. Several types of nano-materials such as clays or montmorillonite [21], double layered hydroxides [23], etc. have been incorporated into epoxy resins aiming to improve flame retardancy. The use of CNTs as flame retardants has raised great interest among re-searchers due to their special properties. CNTs have been used as a flame retardant (Kashiwagi et al. [24]) not only because of sig-nificant improvement of the thermal stability of polymer by their free radical scavenger effect, but also by the formation of a structural network and enhancing the mechanical properties of the final polymer nanocomposite [25]. Moreover, the larger sur-face area of nanotubes can promote the formation of large amount of char residue which prevents the resin from heat degradation, that is to say, they can generate excellent gas barriers which delay the oxidative degradation of resin during the combustion. How-ever, these nano effects will be diminished if nanofillers aggregate together driven by the strong Van der Waals forces. Therefore, high dispersion state of the CNTs constituted a key point for enhancement of the fire retardant properties [26]. Furthermore, the absence of interfacial interaction limits load transfer from epoxy matrix to CNTs due to their atomically smooth non-reactive surface resulting in poor mechanical properties of epoxy nano-composites [27]. Up to now, different approaches have been sug-gested to increase the dispersion degree of CNTs such as ultrasonication, pre-dispersed CNTs into polymer, chemical modification through functionalization [28], etc.

Chemical vapor deposition (CVD) [2] is the most popular method of producing CNTs based on the pyrolysis of hydrocarbons over metal catalysts. In comparison with other synthesis methods it has the advantage of producing aligned CNTs bundles in a single step process, without further purification at a relatively low cost and without prior preparation of substrates [29]. Another impor-tant advantage is the ease for changing gas composition to prepare doped nanotubes with nitrogen $\left(\mathrm{CN}_{\mathrm{x}}\right)$ or oxygen $\left(\mathrm{CO}_{\mathrm{x}}\right)$. Up to know, numerous applications of $\mathrm{CN}_{\mathrm{x}}$ have been reported: field emission devices [30], sensors [8], catalysts [31], electrocatalysts for oxygen reduction reaction [32], and batteries [33]. $\mathrm{CO}_{x}$ has also been pre-pared and studied [34] and interesting applications as catalysts for electrophoresis have been reported [35]. Chemical functionaliza-tion of CNTs to obtain $\mathrm{CN}_{x}$ and $\mathrm{CO}_{x}$ is the strategy explored in this paper to increase polymer-nanotube interaction which leads to the enhanced dispersion state of the functionalized CNTs.

These nanotubes were characterized by $\mathrm{X}$-ray photoelectron spectroscopy (XPS), transmission electron microscopy (TEM), scanning electron microscopy (SEM), X-ray scattering (XRD), Raman spectroscopy, and thermal stability (TGA). Afterwards, the nanotubes were used as flame retardant nano-fillers in epoxy matrix to prepare polymer composites, using a multistage mixing and curing process. The morphology of the resultant epoxy nanocomposites was analyzed by SEM. Their thermal stability was investigated by thermogravimetric analysis (TGA) and dif-ferential scanning calorimetry (DSC). Mechanical properties were determined by dynamic mechanical properties (DMA). The flammability of epoxy nanocomposites was characterized by microscale combustion calorimeter (MCC) and limited oxygen index (LOI).

\section{Experimental procedures}

\subsection{Materials}

Epoxy resin (Diglycidyl ether of bisphenol-A (DGEBA)) (EP) with an equivalent weight per epoxide group of $480 \mathrm{~g} \mathrm{~mol}^{-1}$ and 4, 4'diaminodiphenylsulfone (DDS) with an amine equivalent weight of $140 \mathrm{~g}$ $\mathrm{mol}^{-1}$, Ferrocene $\left(\mathrm{FeCp}_{2}\right)$, Benzylamine, Toluene and the solvents were purchased from Aldrich chemical company and used as received.

\subsubsection{Synthesis of $\mathrm{CNT}, \mathrm{CN}_{\mathrm{x}}$ and $\mathrm{CO}_{\mathrm{x}}$}

2.1.1.1. Synthesis of CNT. A solution consisting of $95 \%$ Toluene and $5 \%$ Ferrocene, which was sonicated for $20 \mathrm{~min}$, was prepared. A single furnace equipped with the CVD technique with a flow of $2.5 \mathrm{~L} \mathrm{~min}-1$ of argon gas for $30 \mathrm{~min}$ at $850^{\circ} \mathrm{C}$ were used to syn-thesize the CNT. Total obtained weight was in the range $0.9 \mathrm{e} 1.7 \mathrm{~g}$ in each synthesis.

2.1.1.2. Synthesis of $\mathrm{CN}_{\mathrm{x}}$. $\mathrm{CN}_{\mathrm{x}}$ were produced using a CVD process using a solution containing 5 wt.\% of ferrocene $\left(\mathrm{FeCp}_{2}\right)$ in benzyl-amine $\left(\mathrm{C}_{7} \mathrm{H}_{9} \mathrm{~N}\right)$. The solution was then heated at $850{ }^{\circ} \mathrm{C}$ with the flow of $2.5 \mathrm{~L} \mathrm{~min}^{-1}$ of argon gas for $30 \mathrm{~min}$. An approximate total weight of $1.2 \mathrm{~g}$ was obtained per each synthesis.

2.1.1.3. Synthesis of $\mathrm{CO}_{x}$. In the case of $\mathrm{CO}_{x}$, a solution containing $94 \%$ Toluene, $1 \%$ Ethanol and $5 \%$ Ferrocene was heated at $850{ }^{\circ} \mathrm{C}$ at $2.5 \mathrm{~L}$ $\mathrm{min}^{-1}$ of argon gas for $30 \mathrm{~min} .0 .8 \mathrm{e} 0.95 \mathrm{~g}$ total weight was obtained in each synthesis.

All of these synthesized nanotubes, $\mathrm{CO}_{x}, \mathrm{CN}$ and $\mathrm{CNT}$ were purified and improved their epoxy dispersibility by $\mathrm{H}_{2} \mathrm{O}_{2}$ eUV method described in our previous work [36].

\subsubsection{Preparation of epoxy nanocomposites}

Three samples containing $2 \mathrm{wt} . \%$ nanotubes $\left(\mathrm{CNT}, \mathrm{CN}_{\mathrm{x}}\right.$ or $\mathrm{CO}_{\mathrm{x}}$ ), were prepared using a three roll mill mixing appropriate amounts of EP and nanotubes at $120^{\circ} \mathrm{C}$ to decrease epoxy viscosity. After milling, the mixture was gently stirred at the same temperature to partially eliminate trapped air from the mixture. Stoichiometric amount of DDS was then added to the mixture and the temperature was then increased to $130^{\circ} \mathrm{C}$ to dissolve the curing agent for 20 min under vacuum to get a clear, homogeneous and degassed mixture. The mixture was then poured into a preheated Teflon mold and cured in an oven at $140{ }^{\circ} \mathrm{C}$ for $5 \mathrm{~h}$ and then post cured for $3 \mathrm{~h}$ at $180^{\circ} \mathrm{C}$. Specimens for the entire tests were cut from this block. The sample without nanotubes was the reference.

\subsection{Instrumentation}

X-ray photoelectron spectroscopy (XPS) data were recorded with an Omicron spectrometer equipped with an EA-125 hemi-spherical electron multichannel analyzer and an unmonochrom-atized Mg Ka X-ray source operating at $150 \mathrm{~W}$ with pass energy of $50 \mathrm{eV}$. The recorded spectra were analyzed using CASAXPS soft-ware, and RSF database by peak fitting after Shirley background correction.

$X$-ray diffraction (XRD) was collected in an automatic X'Pert Philips diffractometer using a Cu source. Data were collected in the $2 \mathrm{q}$ range from $10^{\circ}$ to $90^{\circ}$ in step-scanning mode with a step size of $0.02^{\circ}$ and a counting time of $2 \mathrm{~s}$ per step.

Scanning Electron Microscopy (SEM) was performed using a FEl equipment, with a voltage of $10 \mathrm{kV}$ and a secondary electron detector. The nanocomposites samples were sputter-coated in gold prior to the observation.

Raman spectroscopy measurements were carried out in via 
Renishaw confocal microscope based Raman spectrometer using the $514.5 \mathrm{~nm}$ laser excitation. For each sample, various spectra were recorded in different places in order to verify the homogeneity of the sample.

Thermogravimetric analysis (TGA) was performed in a TGA Q50 (TA Instruments) system heating from room temperature to $800{ }^{\circ} \mathrm{C}$. Approximately $5 \mathrm{mg}$ of sample were heated in an open Pt crucible at a rate of $10{ }^{\circ} \mathrm{C} \mathrm{min}{ }^{-1}$ under $\mathrm{N}_{2}\left(90 \mathrm{~mL} \mathrm{~min}{ }^{-1}\right)$. Experi-ments in air atmosphere were also run.

Differential scanning calorimetry (DSC) was used to deter-mine the glass transition temperature $(\mathrm{Tg})$ of the nanocomposites using a Mettler Toledo DSC 822 with a liquid nitrogen reservoir. Samples of about $5 \mathrm{mg}$ were scanned from $25^{\circ} \mathrm{C}$ to $250{ }^{\circ} \mathrm{C}$ at $10^{\circ} \mathrm{C} \cdot \mathrm{min}^{-1}$. In order to minimize the effects of previous thermal history, data from a second scan were used for analysis.

Dynamic mechanical properties (DMA) were measured using a DMTA Q800 Dynamic Mechanical Analyzer (TA Instruments), with amplitude of $30 \mathrm{~mm}$ at $1 \mathrm{~Hz}$. Nanocomposite specimens with nominal dimensions of $60 \times$ $10 \times 2 \mathrm{~mm}^{3}$ were mechanically tested in single cantilever mode. The samples were heated from room temperature to $250{ }^{\circ} \mathrm{C}$ at a linear rate of $3{ }^{\circ} \mathrm{C} \cdot \mathrm{min}^{-1}$.

Microscale combustion calorimetry (MCC) (Fire Testing Technology, UK) was used to investigate the combustion of nano-composites according to ASTM D7309. About $5 \mathrm{mg}$ of sample were heated up to $700{ }^{\circ} \mathrm{C}$ at $1{ }^{\circ} \mathrm{C} . \mathrm{s}^{-1}$ under nitrogen at $80 \mathrm{~cm}^{3} \mathrm{~min}^{-1}$. The volatile and anaerobic thermal degradation products in the nitro-gen stream were mixed with a $20 \mathrm{~cm}^{3}$ $\min ^{-1} \mathrm{~N}_{2} / \mathrm{O}_{2}$ stream $\left(20 \% \mathrm{O}_{2}\right)$ prior entering the combustion furnace at 900 ${ }^{\circ} \mathrm{C}$. Each sample was run in three replicates.

Limiting oxygen index (LOI) values were carried out using an Oxygen Index instrument (Fire Testing Technology, UK) according to ASTM D 2863-97. The sample dimensions were $130 \times 6.5 \times 3.2 \mathrm{~mm}^{3}$. The experimental error in LOI estimation was $\pm 0.2 \%$.

\section{Results \& discussion}

\subsection{Characterization of nanotubes}

Fig. 1 shows SEM images of different types of CNTs with their typical tubular structure. Dimensions (length and diameter) were determined over 500 nanotubes for each sample; histograms are presented in Figs. $1 S$ and $2 S$ and averages are summarized in Table 1 . It can be observed the tendency of nanotubes to present a notably higher length to diameter ratio. This is not surprising since
Table 1

Dimensions of $\mathrm{CNT}, \mathrm{CO}_{\mathrm{x}}$ and $\mathrm{CN}_{\mathrm{x}}$.

\begin{tabular}{llll}
\hline Sample & $\begin{array}{l}\text { Length } \\
(\mu \mathrm{m})\end{array}$ & $\begin{array}{l}\text { Diameter } \\
(\mathrm{nm})\end{array}$ & Length/Diameter Ratio \\
\hline $\mathrm{CNT}$ & $142 \pm 32$ & $75 \pm 20$ & 1893 \\
$\mathrm{CO}_{\mathrm{x}}$ & $182 \pm 40$ & $61 \pm 16$ & 2983 \\
$\mathrm{CN}_{\mathrm{x}}$ & $136 \pm 20$ & $91 \pm 18$ & 1495 \\
\hline
\end{tabular}

it has already been reported that oxygen in the gas feed (ethanol) helps to keep the Fe catalyst clean from carbon agglomeration and active for longer periods, thus resulting in longer nanotube [34].

TEM images of $\mathrm{CNT}, \mathrm{CO}_{\mathrm{x}}$ and $\mathrm{CN}_{\mathrm{x}}$ disclosing graphitic layers for the two former, and the characteristic stacked bamboo-like tubules for $\mathrm{CN}_{\mathrm{X}}$ are presented in Fig. 2. It should be noted the surface roughness found for COx.

The thermal stability of nanotubes was characterized by TGA in air and $\mathrm{N}_{2}$ atmospheres (Fig. $3 \mathrm{~S}$ and Table $1 S$ ). CNT's presented the highest thermal stability and the lower values of the degradation temperature for $\mathrm{CO}_{\mathrm{x}}$ and $\mathrm{CN}_{\mathrm{x}}$ were attributed to the presence of defects induced by doping and considerably more edge plane sites [36] that facilitate high temperature oxidation. Moreover, among the doped nanotubes, $\mathrm{CO}_{\mathrm{x}}$ presents the highest weight reduction rate at the lowest temperature reflecting that this kind of nano-tubes are much more reactive than $\mathrm{CNT}$ or $\mathrm{CN}_{\mathrm{x}}$; intuitively, the surface roughness and the surface functionalities of these tubes may contribute to increase its reactivity. However, these doped nanotubes are more thermally stable than oxygen and nitrogen functionalized nanotubes obtained by chemical treatments of pristine CNT either in solution or in gas phase [37].

Raman characterization and XRD analysis (Fig. 4S and 5S) were used to know the quality of crystallinity and defect of synthesized carbon nanotubes. According to these results, CNTs has a higher degree of crystallinity in comparison with $\mathrm{CO}_{\mathrm{x}}$ and $\mathrm{CN}_{\mathrm{x}}$ which is in agreement with TGA results.

Based on the XPS results (Fig. 6S and Table 2S), 91.5\% of carbon atoms of CNT are either aromatic or aliphatic and present the highest percentage of $\mathrm{C}] \mathrm{C}$ bonding compared to doped nanotubes. For $\mathrm{CO}_{\mathrm{x}}$ and $\mathrm{CN}_{\mathrm{X}}$ the fraction of oxidized carbon atoms is about $15 \%$ being the amount of $\mathrm{N}$ atoms in the structure of $\mathrm{CN}_{\mathrm{X}}$ of $1.9 \%$. All these doping provide great reactivity and solubility which play an important role in the preparation of polymer nanocomposites and to achieve enhanced interfacial interaction between nanotubes and polymers.

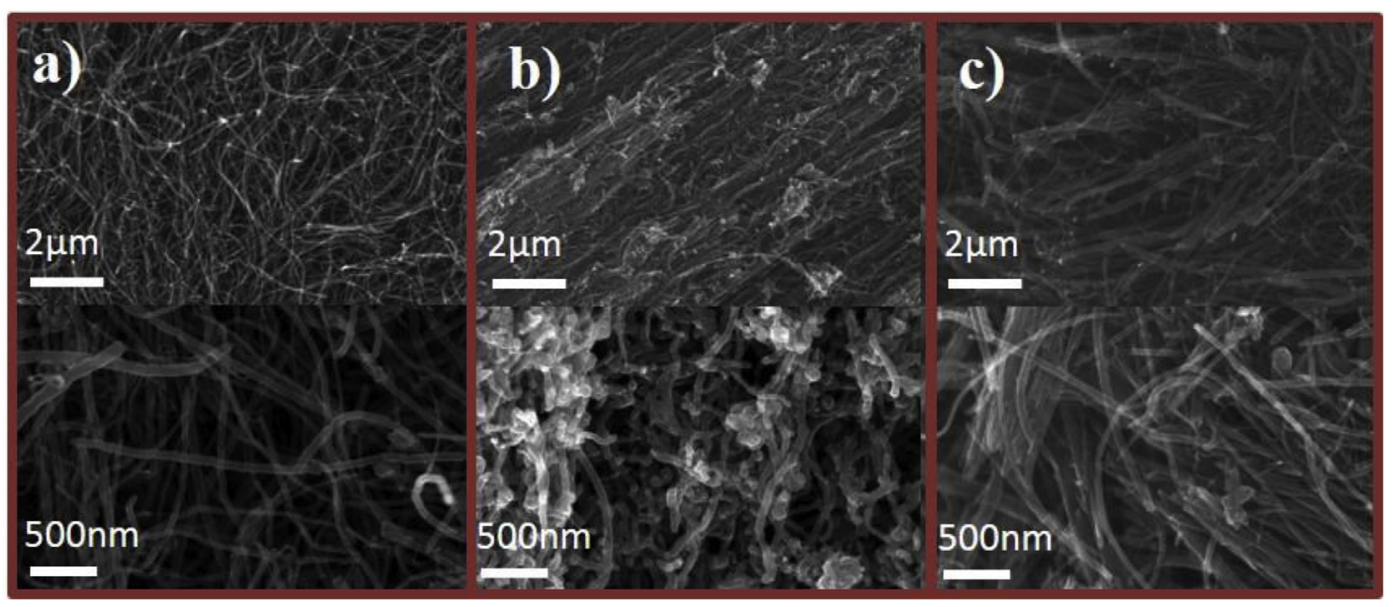

Fig. 1. SEM image of: a) $\mathrm{CNT}$, b) $\mathrm{CO}_{\mathrm{x}}$ and c) $\mathrm{CN}_{\mathrm{x}}$ at two different magnifications. (A colour version of this figure can be viewed online.) 


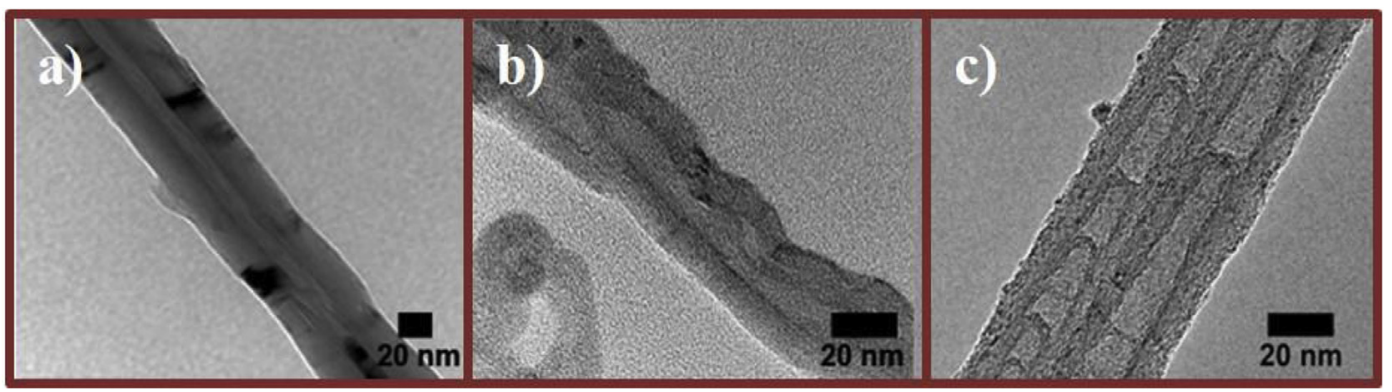

Fig. 2. TEM image of: a) $\mathrm{CNT}$; b) $\mathrm{CO}_{\mathrm{x}}$; and c) $\mathrm{CN}_{\mathrm{x}}$. (A colour version of this figure can be viewed online.)

\subsection{Thermal stability and mechanical behavior of epoxy nanocomposites}

The influence of the pristine and doped CNTs on the thermal stability of epoxy nanocomposites was investigated by TGA, as shown in Fig. 3 and Table 2.

Pure epoxy shows a sharp mass loss in the temperature range of $400 \mathrm{e} 450{ }^{\circ} \mathrm{C}$, and its residual mass percentage is $13.3 \%$ under $\mathrm{N}_{2}$ atmosphere. The introduction of either pristine or doped CNT caused the earlier initial decomposition of the nanocomposites in about $16{ }^{\circ} \mathrm{C}$ as reflected by $T_{5 \%}$ and $T_{\max }$ data. This effect may be attributed to the high thermal conductivity of the nanofillers. However, as degradation starts under $\mathrm{N}_{2}$ atmosphere, a char layer begins to be formed; this layer has a protective effect and it should be therefore expected a delay or reduction of gaseous products. This is just what was observed since the incorporation of the nanotubes led to an increase in the char yield at 700 ${ }^{\circ} \mathrm{C}$ in about $6 \mathrm{e} 10 \%$ (Table 2) following the sequence $\mathrm{CO}_{\mathrm{x}} / \mathrm{EP}>\mathrm{CNT} / \mathrm{EP}>$ $\mathrm{CN}_{\mathrm{x}} / \mathrm{EP}$. Notably, these experimental char residues were higher than the calculated ones assuming additivity of char residue (see Table $1 \mathrm{~S}$ for the weight loss under $\mathrm{N}_{2}$ at $700{ }^{\circ} \mathrm{C}$ ), suggesting the existence of synergism among the modifiers. Furthermore, it is interesting to note that the thermal oxidative resistance of the nanocomposites close correlates with the length to diameter ratio of the nanotubes (Table 1): it seems that the higher length to diameter ratio, the higher char yield is produced, and this suggests to be an effect of the percolative network formed by the nanotubes as already

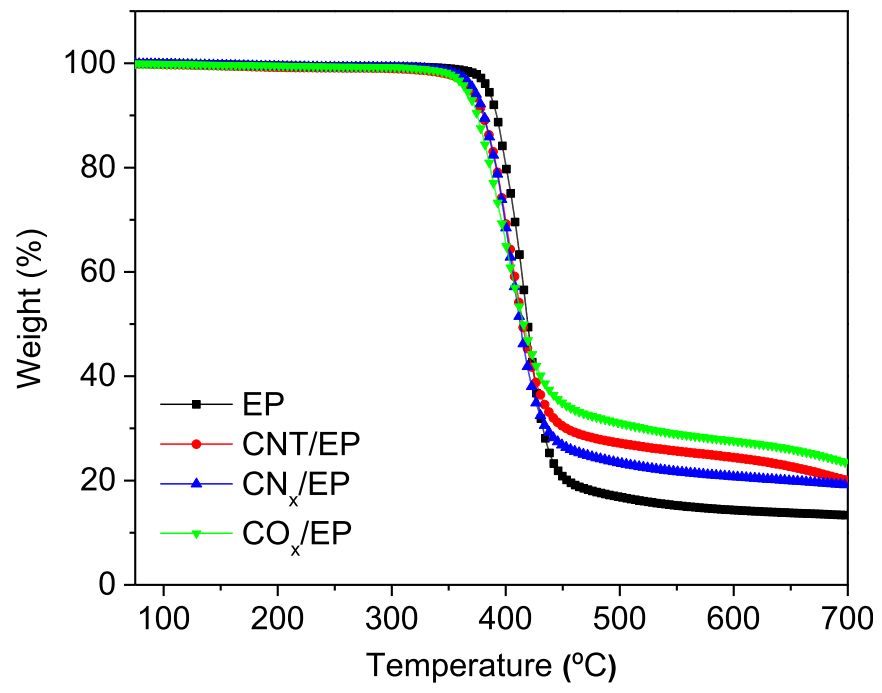

Fig. 3. TGA curve of epoxy and its nanocomposites in $\mathrm{N}_{2}$. (A colour version of this figure can be viewed online.)
Table 2

The TGA data of EP and its nanocomposites.

\begin{tabular}{llllll}
\hline Sample & $\begin{array}{l}\mathrm{T}_{5 \%} \\
\left({ }^{\circ} \mathrm{C}\right)\end{array}$ & $\begin{array}{l}\mathrm{T}_{\max } \\
\left({ }^{\circ} \mathrm{C}\right)\end{array}$ & $\begin{array}{l}(\mathrm{dm} / \mathrm{dt})_{\max } \\
\left({ }^{\circ} \mathrm{C}^{-1}\right)\end{array}$ & \multicolumn{2}{c}{ wt.\% residue yield at $700{ }^{\circ} \mathrm{C}$} \\
\cline { 5 - 6 } & & & & Experimental & Calculated \\
\hline $\mathrm{EP}$ & 384.6 & 418 & 1.9 & 13.3 & - \\
$\mathrm{CNT} / \mathrm{EP}$ & 369.3 & 402 & 1.4 & 19.9 & 15.0 \\
$\mathrm{CN}_{\mathrm{x}} / \mathrm{EP}$ & 371.4 & 404 & 1.5 & 19.1 & 15.0 \\
$\mathrm{CO}_{x} / \mathrm{EP}$ & 365.3 & 401 & 1.1 & 23.4 & 14.9 \\
\hline
\end{tabular}

suggested by other authors [38].

However, analysis of char residue is concerned with the end of the degradation process and some effect of the percolative network should be expected at any other stage of the process. We have carefully examined the TGA thermograms of both the pure nano-tubes and the nanocomposites and we have found a significant difference in the maximum rate at which weight is lost, $\partial \mathrm{dm}=\mathrm{dtP}_{\max }$ which can be considered as a measure of the degradation rate. Among the three tubes examined in this work, $\mathrm{CO}_{x}$ presents the maximum degradation rate (Table $1 S$ ) in air but when it is incor-porated into the epoxy, the resulting nanocomposite presents the lowest degradation rate (Table 2). The three nanotubes lower the degradation rate of pure epoxy but $\mathrm{CO}_{x}$ almost halves the value. Since $\mathrm{CO}_{\mathrm{x}}$ alone degrades quickly in air, this effect may be also associated to its high aspect ratio.

The existence of a CNT network was confirmed by a detailed microscopic examination of cryo-fractured specimens. Fig. 4 pre-sents some representative examples of the different microstruc-tural features of the nanocomposites.

A representative image of the dispersion degree is presented in Fig. 4a were it can be observed an apparently homogeneous dis-tribution of the nanofiller on the surface of CNT nanocomposites. The surfaces of $\mathrm{CN}_{\mathrm{x}}$ and $\mathrm{CO}_{\mathrm{x}}$ appear to be similar. Some aggregates, as depicted in Fig. $4 \mathrm{~b}$ and $\mathrm{d}$, were observed for $\mathrm{CNT}$ and $\mathrm{CN}_{\mathrm{x}}$ nanocomposites while no aggregates could be observed for $\mathrm{CO}_{\mathrm{x}}$. Concerning the interfacial contact, we have observed a wide range of cases within the same samples. In some cases a complete decoupling of the nanotubes from the matrix was observed (Fig. 4b) but inspection of other portions of the same sample revealed a good interaction of the tubes (Fig. 4c). So we can conclude that there are no specific features of the microstructure of the nanocomposites that could be attributable to the effect of doping except for the case of oxygen doping. However, the most interesting finding appears in Fig. 4e, were inspection inside a defect free of polymer matrix revealed the presence of a network of interconnected nanotubes, confirming thus the existence of a percolative network.

The influence of addition of nanofillers on the relaxational and mechanical behavior of nanocomposites has been evaluated also by DSC and DMTA. Glass transition temperatures of all the composites were measured by DSC, and DMTA (maximum in tand, Fig. 5) and 


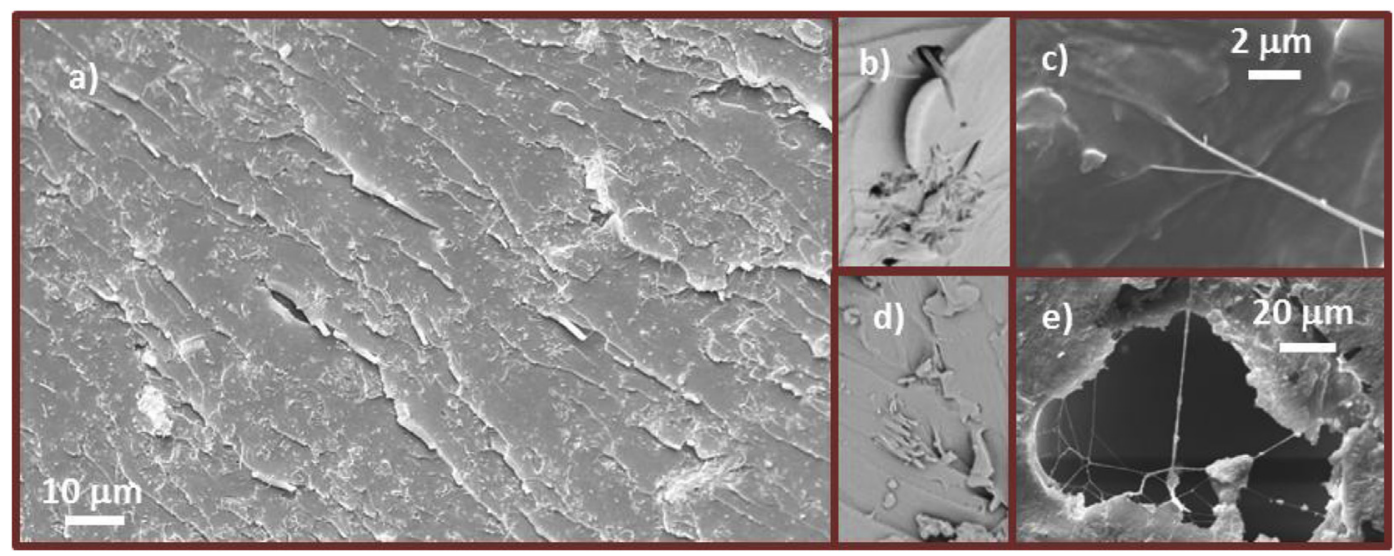

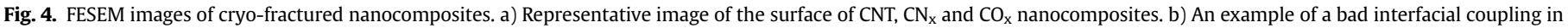

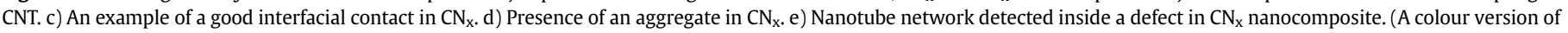
this figure can be viewed online.)

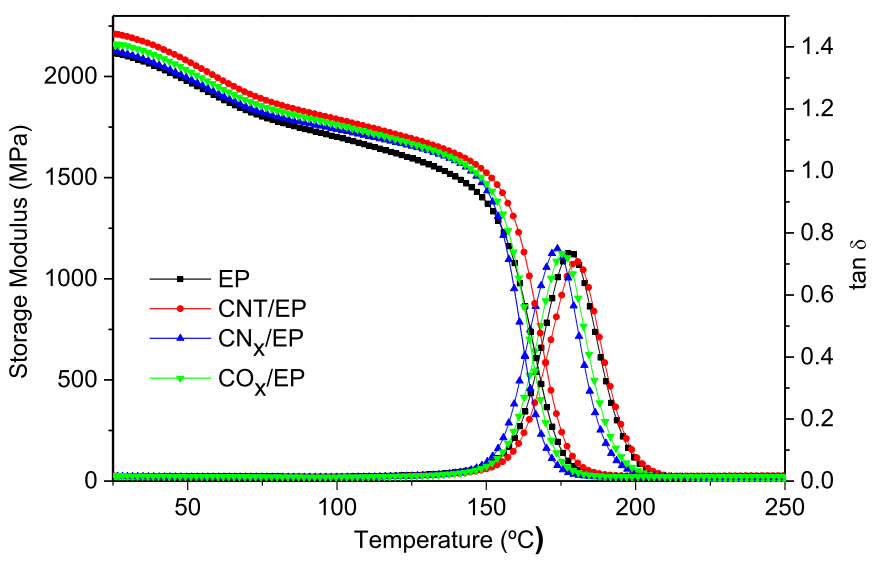

Fig. 5. Storage modulus and tan d versus temperature plots of epoxy and its com-posites. (A colour version of this figure can be viewed online.)

the results are summarized in Table 3.

Reported values of the Tg for epoxy resins cured with DDS are in the range $184{ }^{\circ} \mathrm{C}$ [39] to $230{ }^{\circ} \mathrm{C}$ [40]. Differences with our case are attributed to the high molecular weight of the prepolymer used in this work $(480 \mathrm{~g} /$ mol instead of the usual $340 \mathrm{~g} / \mathrm{mol}$ used by other authors).

Storage modulus (Fig. 5) shows an apparent drop at about $60^{\circ} \mathrm{C}$ that is attributed to the tail of the $\mathrm{b}$ relaxation that typically appears at $-59{ }^{\circ} \mathrm{C}$, as reported by other authors on a similar system [40]. R.t. values are presented in Table 3. No significant variations were found in the $\mathrm{Tg}$ on adding $2 \%$ nanotubes. Neither in the storage modulus nor in the width of the loss tangent peak meaningful al-terations were detected as well. Bad CNT-Epoxy interfacial in-teractions usually manifest as a decrease in both, the storage

Table 3

DSC and DMA results for nanocomposites.

\begin{tabular}{lllll} 
Sample & $\begin{array}{l}\operatorname{Tg}\left({ }^{\circ} \mathrm{C}\right) \\
(\mathrm{DSC})\end{array}$ & $\begin{array}{l}\operatorname{Tg}\left({ }^{\circ} \mathrm{C}\right) \\
(\mathrm{DMTA})\end{array}$ & $\begin{array}{l}\mathrm{E}^{\prime} \\
(\mathrm{GPa})\end{array}$ & FWHM $^{\mathrm{a}}$ \\
\hline $\mathrm{EP}$ & 179 & 178 & 2.11 & 23 \\
$\mathrm{CNT} / \mathrm{EP}$ & 178 & 180 & 2.21 & 22 \\
$\mathrm{CO}_{\mathrm{x}} / \mathrm{EP}$ & 177 & 175 & 2.13 & 21 \\
$\mathrm{CN}_{\mathrm{x}} / \mathrm{EP}$ & 174 & 178 & 2.11 & 23 \\
\hline
\end{tabular}

${ }^{\mathrm{a}}$ Full width at half maximum. modulus and $\mathrm{Tg}$ and it is usually justified as an increase in free volume. Our results indicate that addition of nanofillers do not negatively affect the relaxational and mechanical behavior of the nanocomposites.

\subsection{Flammability}

The three different types of CNTs (CNT, $\mathrm{CO}_{\mathrm{x}}$ and $\mathrm{CN}_{\mathrm{x}}$ ) have been incorporated into the epoxy matrix and their flammability was examined by measuring their limiting oxygen index (LOI); results are summarized in Fig. 6.

Pure epoxy exhibited a LOI value of $21.5 \%$, indicating an easily ignited material. With the addition of $2 \mathrm{wt} . \% \mathrm{CNT}$, the LOI of the resultant epoxy composite increases to $33.5 \%$. LOI values above 27 are normally indicative of materials that are self-extinguishing [41]. The incorporation of $\mathrm{CO}_{x}$ into epoxy results in a highest LOI value of $35 \%$. In contrast, the addition of $\mathrm{CN}_{\mathrm{x}}$ does not lead to a significant increment in $\mathrm{LOI}$ as $\mathrm{CO}_{\mathrm{x}}$, but still exhibiting a high LOI value of $31.5 \%$. In terms of LOI increment: $12 \%$ (CNT), $13.5 \%\left(\mathrm{CO}_{x}\right)$ and $10 \%\left(\mathrm{CN}_{\mathrm{x}}\right.$.

Obviously, LOI values of the composites strongly depend on the LOI value of the polymer matrix and on the presence of other ad-ditives. Therefore, a more indicative parameter of the effect of

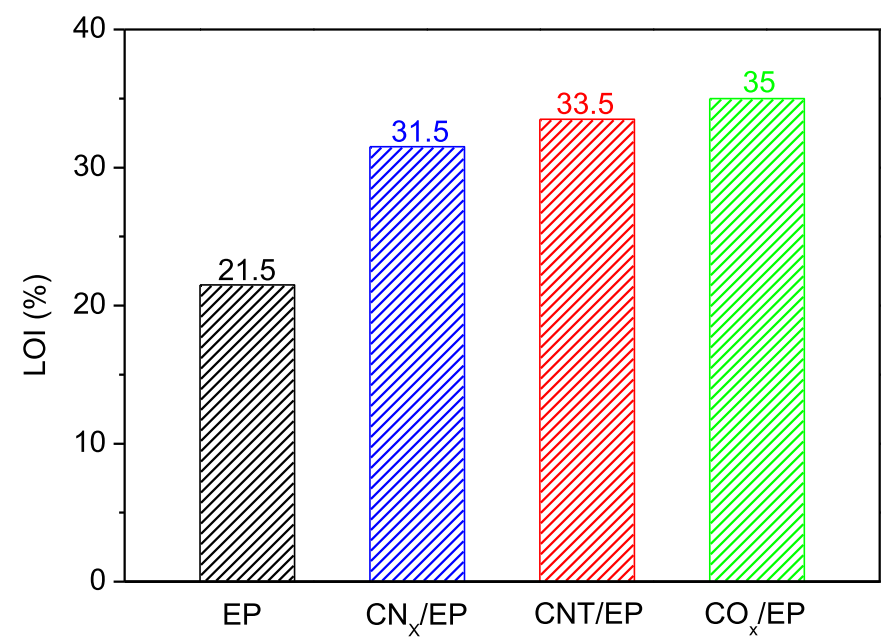

Fig. 6. LOI data of pure EP and its nanocomposites. (A colour version $\mathrm{gf}$ this figure can be viewed online.) 
carbon nanofillers may be the LOI increment with respect to the same material without carbon nanofillers. A literature search on the maximum LOI increments found for epoxy thermosets modified with carbon nanotubes yields the following data: $0.2 \%$ for epoxy loaded with double walled CNT [42], 3\% for epoxy with CNT syn-thesized by the sol-gel method [43], 5\% for epoxy with amino functionalized CNT [44]. Therefore, it seems that the LOI in-crements found in this paper represent the maximum values ever reported for epoxy thermosets.

Complimentary data to TGA and LOI experiments are supplied by micro-scale combustion calorimetry (MCC) experiments, a testing technique that provides a variety of information on the combustion behavior of polymeric materials [45].

The relevant parameters obtained from the MCC include peak heat release rate $(\mathrm{pHRR})$, total heat released (THR), temperature at $\mathrm{pHRR}$ $\left(T_{\max }\right)$ and char yield. Results are depicted in Fig. 7 and Table 4.

Table 4 shows that pHRR and THR of neat epoxy (EP) are reduced by $22.7 \%$ and $25.3 \%$ respectively, by the addition of $2 \mathrm{wt} . \%$ of $\mathrm{CN}_{\mathrm{x}}$. A further minor reduction in PHRR and THR was achieved by the incorporation of CNTs in comparison with the sample containing $\mathrm{CN}_{\mathrm{x}}$. However, the highest reduction in pHRR $(38.7 \%)$ and THR $(32.8 \%)$ was achieved by incorporation of $2 \mathrm{wt} . \%$ of $\mathrm{CO}_{\mathrm{x}}$ into the epoxy matrix. These results are in accordance with previously re-ported experiments on polypropylene/ MWCNT at low loadings [38]. It can be also noted from Table 4 that the char residue increased on addition of nanotubes in accordance with TGA results presented previously (Table 2), except for the $\mathrm{CN}_{\mathrm{x}}$ case. Interest-ingly, char residue for $\mathrm{CO}_{\mathrm{x}}$ composites is higher than the char res-idue of pure epoxy plus amount of nanotubes, indicating that the tubes may induce some additional charring ( $\sim 5 e 7 \%)$ of the epoxy matrix.

The surface morphology of the samples after LOI test was observed by SEM and presented in Fig. 8. EP, CNT/EP and $\mathrm{CN}_{\mathrm{x}} / \mathrm{EP}$ (Fig. 8a, b and c) nanocomposites showed a fluffy and cracked char layer full of open holes all along the surface; however $\mathrm{CO}_{\mathrm{x}} / \mathrm{EP}$ dis-played a thick and homogeneous layer which may explain the significant reduction of heat and mass transfer associated to the enhanced flame retardancy presented by the nanocomposites made with this filler Based on the LOI and MCC results, the COx/EP system is

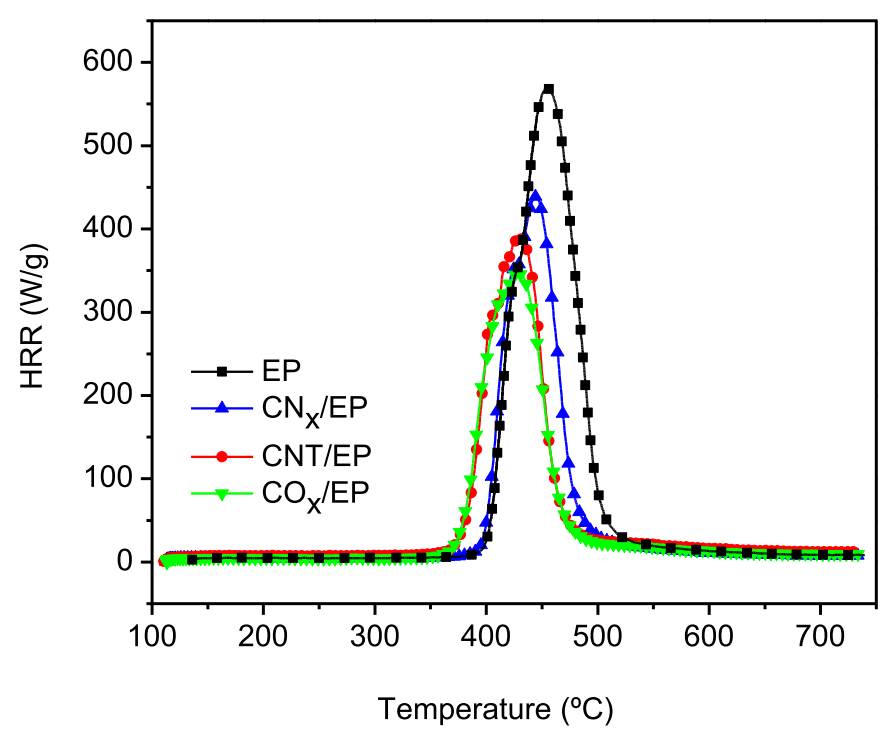

Fig. 7. The HRR curves of samples from MCC. (A colour version of this figure can be viewed online.)
Table 4

Peak heat release rate (pHRR), total heat released (THR), temperature at pHRR and char residue as obtained from MCC measurements.

\begin{tabular}{lllll}
\hline Sample & pHRR $(\mathrm{W} / \mathrm{g})$ & $\mathrm{THR}(\mathrm{KJ} / \mathrm{g})$ & $\mathrm{T}_{\max }\left({ }^{\circ} \mathrm{C}\right)$ & Residue $(\%)$ \\
\hline $\mathrm{EP}$ & $568 \pm 15$ & $33.2 \pm 0.9$ & $454 \pm 13$ & $12.1 \pm 0.2$ \\
$\mathrm{CN}_{\mathrm{x}} / \mathrm{EP}$ & $439 \pm 12$ & $24.8 \pm 1.1$ & $444 \pm 9$ & $14.0 \pm 0.1$ \\
$\mathrm{CNT} / \mathrm{EP}$ & $384 \pm 16$ & $23.0 \pm 0.3$ & $433 \pm 8$ & $16.4 \pm 0.3$ \\
$\mathrm{CO}_{\mathrm{x}} / \mathrm{EP}$ & $348 \pm 14$ & $22.3 \pm 1.2$ & $429 \pm 4$ & $18.9 \pm 0.3$ \\
\hline
\end{tabular}

illustrative of a condensed phase burning mechanism with a significantly lower mass loss and higher char yield compared to the other samples.

The higher char residue resulted in quenching the fire which means less epoxy converted into combustible fuel. The early appearance of a network structure on the external surface of the sample (Scheme 1b) right after the ignition, followed by formation of a thick char layer, served as a thermal barrier to separate burning materials from oxygen [46] also preventing feeding the flame zone from combustible gases, as shown in (Scheme 1c). This is the commonly accepted mechanism for the effect of CNTs in all the studied samples. The specific reason why $\mathrm{CO}_{x} / \mathrm{EP}$ composite pre-sents notably enhanced flame retardancy may be associated to its very large aspect ratio. Theoretical studies on the critical fractional volumes associated with the onset of percolation for randomly oriented CNTs demonstrate that this critical parameter is inversely proportional to the aspect ratio [47], reaching extremely low percolation limits ( 0.01\%) at high aspect ratio values ( 2000). At the loadings used in this work ( 2 wt.\%) the percolative network must be dense enough to form a protective barrier even consid-ering nanotube fragmentation during the preparation of the nanocomposites (three roll mill) or aggregate formation. This experimental finding suggests the need of exploring the flame retardancy properties of systems with varying aspect ratio which is the aim of our ongoing research.

\section{Conclusions}

In the current work, three different types of CNTs (CNT, $\mathrm{CO}_{\mathrm{x}}$ and $\mathrm{CN}_{\mathrm{X}}$ ) were synthesized by using CVD method and characterized by XRD, Raman, XPS, SEM and TEM. The lengths of the nanotubes were above $136 \mu \mathrm{m}$, the diameters ranged between 60 and $90 \mathrm{~nm}$ and $\mathrm{CO}_{\mathrm{x}}$ nanotubes presented the highest aspect ratio near 3000 .

Epoxy nanocomposites containing the three types of carbon nanotubes were prepared by three roll mill at a constant loading of $2 \%$ in an epoxy/DDS thermoset and curing them in two stages to ensure the maximum conversion degree. Morphological observations revealed that the CNTs were homogeneously dispersed in the epoxy matrix. Some aggregates and some regions in which nanotubes were decoupled from the matrix were observed for CNT and $\mathrm{CN}_{\mathrm{x}}$ systems. However, no such defects were observed for $\mathrm{CO}_{\mathrm{x}}$ nanocomposites.

The influence of pristine and doped CNTs on the thermal stability of epoxy nanocomposites was investigated by TGA. The results showed that introduction of the nanofillers at $2 \mathrm{wt}$ \% loading caused the earlier initial decomposition of the nanocomposites, an increased char yield, and a reduction of the degradation rate of in comparison with pure epoxy.

The influence of addition of nanofillers on the relaxational and mechanical behavior of nanocomposites was evaluated by DSC and DMTA. No significant variations in Tg, storage modulus or loss tangent width were detected, indicating that the addition of nanofillers does not negatively affect the relaxational and mechanical response of the nanocomposites.

The flammability behavior of nanocomposites was investigated 


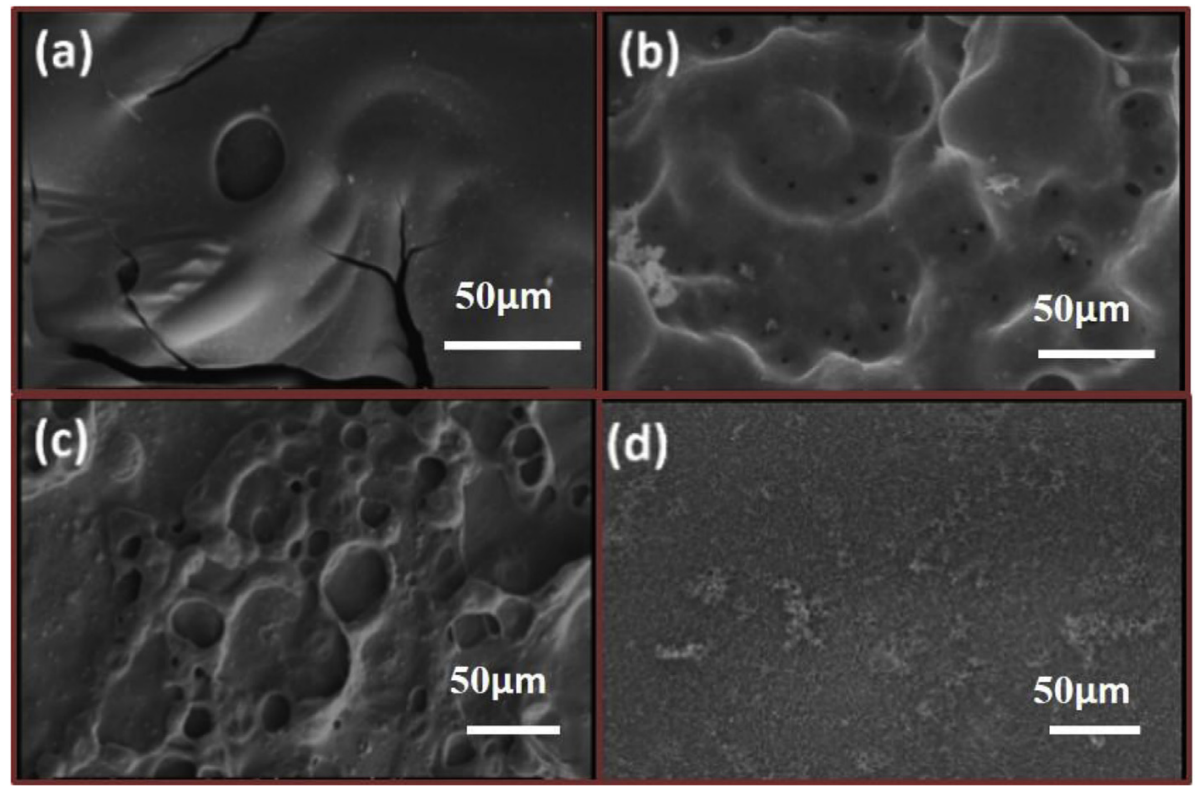

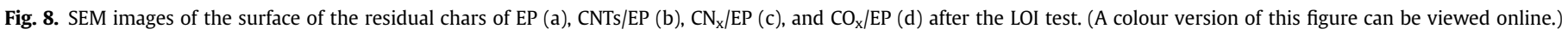

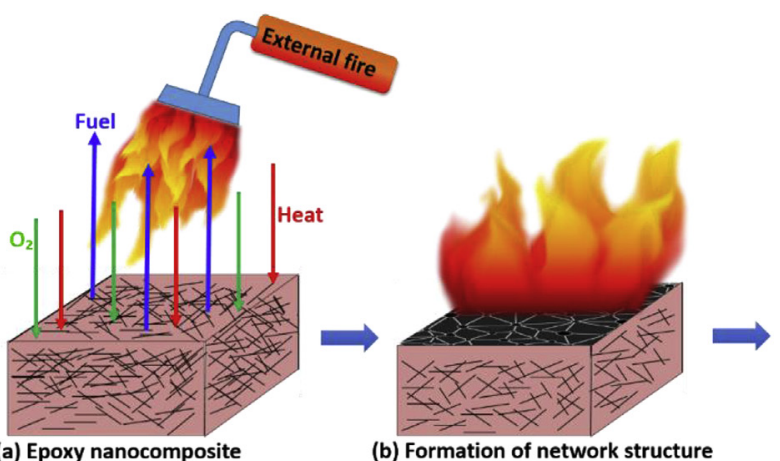

(a) Epoxy nanocomposite (b) Formation of network structure

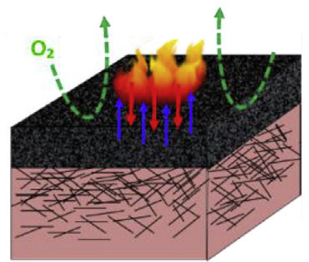

(c) Self extinguish property

Scheme 1. A proposed flame retardant action.

by LOI and MCC. The LOI increments for $\mathrm{CN}_{\mathrm{x}}, \mathrm{CNT}$ and $\mathrm{CO}_{\mathrm{x}}$ nanocomposites were observed $31.5,33.5$ and 35 respectively, being the latter the highest increment observed for epoxy doped with carbon nanotubes.

The MCC results showed a remarkable reduction in pHRR and THR of $38.7 \%$ and $32.8 \%$ respectively for $\mathrm{CO}_{\mathrm{x}}$ system.

From the SEM images taken from the residual char layer formed by $\mathrm{CO}_{\mathrm{x}}$ nanocomposite after burning, a uniform and continuous char layer was observed. However, the other studied systems presented a fluffy surface plenty of open holes.

In the absence of specific effects that could be associated to the surface chemical nature of the carbon nanotubes, our results suggest that the effective improvement in the flame retardant properties of the studied nanocomposites is due to a homogeneous dispersion of CNTs in the epoxy matrix. In the case of oxygen doped carbon nanotubes, which presents notably enhanced flame retardancy, a more effective barrier was formed and this finding may be associated to the formation of a denser percolative network due to its very large aspect ratio. Hence, the key role of percolative networks suggests the need of exploring the flame retardancy properties of systems with the varying aspect ratio which is the aim of our ongoing research.

\section{Acknowledgement}

Authors wish to acknowledge financial support from Spanish Ministerio de Economía y Competitividad under grant MAT2014-57557-R. Authors also wish to thank Dr. Sofía M. VegaDíaz for her invaluable help with XPS interpretation.

\section{References}

[1] S. Iijima, Helical microtubules of graphitic carbon, Nature 354 (1991) 56-58, http://dx.doi.org/10.1038/354056a0.

[2] M. Kumar, Y. Ando, Chemical vapor deposition of carbon nanotubes: a review on growth mechanism and mass production, J. Nanosci. Nanotechnol. $10(2010)$ 3739-3758, http://dx.doi.org/10.1166/jnn.2010.2939.

[3] P.J.F. Harris, Carbon nanotube composites, Int. Mater. Rev. 49 (2004) 31-43, http://dx.doi.org/10.1179/095066004225010505.

[4] Tawfik A. Saleh, in: S. Suzuki (Ed.), Syntheses and Applications of Carbon Nanotubes and Their Composites, InTech, 2013, http://dx.doi.org/10.5772/ 3377 (Chapter 21), p. 779-493.

[5] Y. N. Jurn, M. F. Malek, W. Liu, Haider K. Hoomod, A. A. Kadhim, Review Coating methods of carbon nanotubes and their potential applications, 
presented in 4th IEEE International Conference on Control System Computing and Engineering (ICCSCE 2014), Malaysia, November, 2014

[6] L. Shen, C. Yuan, H. Luo, X. Zhang, K. Xu, F. Zhang, In situ growth of Li4Ti5O 12 on multi-walled carbon nanotubes: novel coaxial nanocables for high rate lithium ion batteries, J. Mater. Chem. 21 (2011) 761-767, http://dx.doi.org/ 10.1039/ C0JM02316G

[7] A.S. Brady-Estévez, M.H. Schnoor, C.D. Vecitis, N.B. Saleh, M. Elimelech, Mul-tiwalled carbon nanotube filter: improving viral removal at low pressure, Langmuir 26 (2010) 14975-14982, http://dx.doi.org/10.1021/la102783v.

[8] V.J. Gonzalez, E. Gracia-Espinob, A. Morelos-Gómez, F. López-Uríase, H. Terrones, M. Terrones, Biotin molecules on nitrogen-doped carbon nanotubes enhance the uniform anchoring and formation of $\mathrm{Ag}$ nanoparticles, Carbon 88 (2015) 51-59, http://dx.doi.org/10.1016/j.carbon.2015.02.046.

[9] A. Kausar, I. Rafique, B. Muhammad, A review on applications of polymer/carbon nanotube and epoxy/CNT composites, Polym.-Plast. Technol. Eng. 55 (2016) 1167-1191, http://dx.doi.org/10.1080/03602559.2016.1163588.

[10] Fan-Long Jin, X. Li, Soo-Jin Park, Synthesis and application of epoxy resins: a review, J. Ind. Eng. Chem. 29 (2015) 1-11, http://dx.doi.org/10.1016/ j.jiec.2015.03.026.

[11] Y. Zhoua, J. Fenga, H. Peng, H. Quc, J. Ha, Catalytic pyrolysis and flame retardancy of epoxy resins with solid acid boron phosphate, Polym. Degrad. Stab. 110 (2014) 395-404, http://dx.doi.org/10.1016/ j.polymdegradstab.2014.10.009.

[12] M.M. Hirschler, Flame retardants and heat release: review of traditional studies on products and on groups of polymers, Fire Mater. 39 (2014) 207-231, http://dx.doi.org/10.1002/fam.2243.

[13] H. Xu, Xin-rong Deng, Preparation and properties of superfine $\mathrm{Mg}(\mathrm{OH})_{2}$ flame retardant, Trans. Nonferrous Met. Soc. China 16 (2006) 488-492, http:// dx.doi.org/10.1016/S1003-6326(06)60084-8.

[14] X. Wang, S. Zhou, W. Xing, B. Yu, X. Feng, L. Song, Y. Hu, Self-assembly of Ni-Fe layered double hydroxide/graphene hybrids for reducing fire hazard in epoxy composites, J. Mater. Chem. A 1 (2013) 4383-4390.

[15] W. Jiang, Fan-Long Jin, Soo-Jin Park, Synthesis of a novel phosphorus-nitrogencontaining intumescent flame retardant and its application to fab-rics, J. Ind. Eng. Chem. 27 (2015) 40-43, http://dx.doi.org/10.1016/ j.jiec.2015.01.010.

[16] X. Wang, Y. Hua, L. Song, W. Xing, H. Lua, P. Lv, G. Jie, Flame retardancy and thermal degradation mechanism of epoxy resin composites based on a DOPO substituted organophosphorus oligomer, Polymer 51 (11) (2010) 2435-2445.

[17] X. Wang, W. Xing, X. Feng, B. Yu, L. Song, Y. Hu, Functionalization of graphene with grafted polyphosphamide for flame retardant epoxy composites: syn-thesis, flammability and mechanism, Polym. Chem. 5 (2014) 1145-1154.

[18] S. Song, J. Ma, K. Cao, G. Chang, Y. Huang, J. Yang, Synthesis of a novel dicyclic silicon-/phosphorus hybrid and its performance on flame retardancy of epoxy resin, Polym. Degrad. Stab. 99 (2014) 43-45, http://dx.doi.org/10.1016/ j.polymdegradstab.2013.12.013.

[19] X. Wang, L. Song, H. Yang, W. Xing, B. Kandola, Y. Hu, Simultaneous reduction and surface functionalization of graphene oxide with POSS for reducing fire hazards in epoxy composites, J. Mater. Chem. 22 (2012) 22037-22043.

[20] Shui-Yu Lu, I. Hamerton, Recent developments in the chemistry of halogen-free flame etardant polymers, Prog. Polym. Sci. 27 (2001) 1661-1712, http:// dx.doi.org/10.1016/S0079-6700(02)00018-7.

[21] P. Kiliaris, C.D. Papaspyrides, Polymer/layered silicate (clay) nanocomposites: an overview of flame retardancy, Prog. Polym. Sci. 35 (2010) 902-958, http:// dx.doi.org/10.1016/j.progpolymsci.2010.03.001.

[22] E.N. Kalali, S. De Juan, X. Wang, S. Nie, R. Wang, De-Yi Wang, Comparative study on synergistic effect of LDH and zirconium phosphate with aluminum trihydroxide on flame retardancy of EVA composites, J. Therm. Anal. Calorim. 121 (2015) 619-626, http://dx.doi.org/10.1007/s10973-015-4598-9.

[23] E.N. Kalali, X. Wang, De-Yi Wang, Functionalized layered double hydroxide-based epoxy nanocomposites with improved flame retardancy and mechan-ical properties, J. Mater. Chem. A 3 (2015) 6819-6826, http://dx.doi.org/ 10.1039/ C5TA00010F.

[24] T. Kashiwagi, E. Grulke, J. Hilding, R. Harris, W. Awad, J. Douglas, Thermal degradation and flammability properties of poly(propylene)/carbon nanotube composites, Macromol. Rapid Commun. 23 (2002) 761-765, http://dx.doi.org/ 10.1002/1521-3927(20020901)23:13<761::AID-MARC761>3.0.CO;2-K.

[25] P. Song, L. Xu, Z. Guo, Y. Zhang, Z. Fang, Flame-retardant-wrapped carbon nanotubes for simultaneously improving the flame retardancy and mechan-ical properties of polypropylene, J. Mater. Chem. 18 (2008) 5083-5091, http:// dx.doi.org/10.1039/B808309F.

[26] B. Dittrich, K.A. Warting, D. Hofmann, R. Mulhaupt, B. Schartel, Flame retardancy through carbon nanomaterials: carbon black, multiwall nanotubes, expanded graphite, multi-layer graphene and graphene in polypropylene, Polym. Degrad. Stab. 98 (2013) 1495-1505, http://dx.doi.org/10.1016/ j.polymdegradstab.2013.04.009.

[27] H. Yu, J. Liu, X. Wen, Z. Jiang, Y. Wang, L. Wang, J. Zheng, S. Fu, T. Tang, Charing polymer wrapped carbon nanotubes for simultaneously improving the flame retardancy and mechanical properties of epoxy resin, Polymer 52 (2011) 4891-4898, http://dx.doi.org/10.1016/j.polymer.2011.08.013.

[28] T. Yu, N. Jiang, Y. Li, Functionalized multi-walled carbon nanotube for improving the flame retardancy of ramie/poly(lactic acid) composite, Compos. Sci. Technol. 104 (2014) 26-33, http://dx.doi.org/10.1016/ j.compscitech.2014.08.021.

[29] M.J. Yacaman, M.M. Yoshida, L. Rendon, J.G. Santiesteban, Catalytic growth of carbon microtubules with Fullerene structure, Appl. Phys. Lett. 62 (1993) 202-204, http://dx.doi.org/10.1063/1.108857.

[30] G. Zhou, W. Duan, Field emission in doped nanotubes, J. Nanosci. Nanotechnol. 5 (2005) 1421-1434, http://dx.doi.org/10.1166/jnn.2005.305.

[31] Y. Cao, H. Yu, J. Tan, F. Peng, H. Wang, J. Li, W. Zheng, N.B. Wong, Nitrogenphosphorous- and boron-doped carbon nanotubes as catalysts for the aerobic oxidation of cyclohexane, Carbon 57 (2013) 433-442, http://dx.doi.org/ 10.1016/j.carbon.2013.02.016.

[32] G. Zhong, H. Wang, H. Yu, F. Peng, Nitrogen doped carbon nanotubes with encapsulated ferric carbide as excellent electrocatalyst for oxygen reduction reaction in acid and alkaline media, J. Power Sources 286 (2015) 495-503, http://dx.doi.org/10.1016/j.jpowsour.2015.04.021.

[33] X. Lin, X. Lu, T. Huang, Z. Liu, A. Yu, Xiujing Lin, Xu Lu, Tao Huang, Zhaolin Liu, Aishui Yu, Binder-free nitrogen-doped carbon nanotubes electrodes for lithium-oxygen batteries, J. Power Sources 242 (2013) 855-859, http:// dx.doi.org/10.1016/j.jpowsour.2013.05.100

[34] A. Botello-Mendez, J. Campos-Delgado, A. Morelos-Gomez, J.M. Romo-Herrera, A.G. Rodriguez, H. Navarro, M.A. Vidal, H. Terrones, M. Terrones, Controlling the dimensions, reactivity and crystallinity of multiwalled carbon nanotubes using low ethanol concentrations, Chem. Phys. Lett. 453 (2008) 55-61, http:// dx.doi.org/10.1016/j.cplett.2007.12.073.

[35] V.J. González, C. Martín-Alberca, G. Montalvo, C. García-Ruiz, J. Baselga, M. Terrones, O. Martin, Carbon nanotube-Cu hybrids enhanced catalytic activity in aqueous media, Carbon 78 (2014) 10-18, http://dx.doi.org/10.1016/ MI. carbon.2014.06.014

[36] O. Martin, H.R. Gutierrez, A. Maroto-Valiente, M. Terrones, T. Blanco, J. Baselga, An efficient method for the carboxylation of few-wall carbon nanotubes with little damage to their sidewalls, Mater. Chem. Phys. 140 (2013) 499-507, http:// dx.doi.org/10.1016/j.matchemphys.2013.03.060.

[37] M. Khazaee, W. Xia, G. Lackner, R.G. Mendes, M. Rümmeli, M. Muhler, D.C. Lupascu, Dispersibility of vapor phase oxygen and nitrogen functionalized multi-walled carbon nanotubes in various organic solvents, Sci. Rep. 6 (2016) 26208, http://dx.doi.org/10.1038/srep26208.

[38] T. Kashiwagi, E. Grulke, J. Hilding, K. Groth, R. Harris, K. Butlera, J. Shields, S. Kharchenko, J. Douglas, Thermal and flammability properties of poly-propylene/ carbon nanotube nanocomposites, Polymer 45 (2004) 4227-4239, http:// dx.doi.org/10.1016/j.polymer.2004.03.088

[39] J.K. Lee, K.D. Pae, Mechanical and thermal properties of a diglycidyl ether of bisphenol-a (DGEBA)-4,4'- diaminodiphenyl sulfone (DDS) system cured un-der hydrostatic pressure, Polym. J. 26 (1994) 1093-1099, http://dx.doi.org/ 10.1295 polymj.26.1093.

[40] S.G. Prolongo, M.R. Gude, A. Ureña, Improving the flexural and thermo-mechanical properties of amino-functionalized carbon nanotube/epoxy composites by using a pre-curing treatment, Compos. Sci. Technol. 71 (2011) 765-771, http:// dx.doi.org/10.1016/j.compscitech.2011.01.028.

[41] H.G. Elias, Macromolecules: Synthesis, Materials, and Technology, vol. 2, Plenum Press, New York, 1984, p. p 1137.

[42] C. Katsoulis, E. Kandare, B.K. Kandola, The effect of nanoparticles on structural morphology, thermal and flammability properties of two epoxy resins with different functionalities, Polym. Degrad. Stab. 96 (2011) 529-540, http:// dx.doi.org/10.1016/j.polymdegradstab.2011.01.002.

[43] C. Kuan, W. Chen, Y. Li, C. Chen, H. Kuan, C. Chiang, Flame retardance and thermal stability of carbon nanotube epoxy composite prepared from sol-gel method, J. Phys. Chem. Solids 71 (2010) 539-543.

[44] M. Hesami, R. Bagheri, M. Masoomi, Combination effects of carbon nanotubes, MMT and phosphorus flame retardant on fire and thermal resistance of fiber-reinforced epoxy composites, Iran. Polym. J. 23 (2014) 469-476, http:// dx.doi.org/10.1016/j.jpcs.2009.12.031.

[45] R.E. Lyon, R. Walters, A Microscale Combustion Calorimeter, report DOT/FAA/ AR-01/117, U.S. Department of Transportation ,Office of Aviation Research, Washington DC, 2002

[46] Y. Hu, P. Xu, H. Gui, X. Wang, Y. Ding, Effect of imidazolium phosphate and multiwalled carbon nanotubes on thermal stability and flame retardancy of polylactide, Compos. Part A 77 (2015) 147-153, http://dx.doi.org/10.1016/ j.compositesa.2015.06.025.

[47] M. Foygel, R.D. Morris, D. Anez, S. French, V.L. Sobolev, Theoretical and computational studies of carbon nanotube composites and suspensions: electrical and thermal conductivity, Phys. Rev. B 71 (2005) 104201, http:// dx.doi.org/10.1103/PhysRevB.71.104201. 